\title{
Differentiating muscle relaxant syringes to reduce syringe swap error
}

\author{
Christopher L. Pysyk, MD, FRCPC
}

Received: 22 January 2018/Revised: 11 February 2018/ Accepted: 12 February 2018/Published online: 21 February 2018

(c) Canadian Anesthesiologists' Society 2018

\section{To the Editor,}

Despite efforts to increase the availability and use of medication labels in anesthesiology practice, syringe swap errors continue to be an issue. Syringe swap errors of particular concern to patients and anesthesia providers involve unintended neuromuscular blocking agent administration before sufficient hypnosis has been provided. Using a perioperative incident reporting system, Gisvold and Fasting showed that 27 of 28 (98\%) syringe swaps involved syringes of the same size, with the majority of these reports related to neuromuscular blocking agents given at induction of general anesthesia. ${ }^{1}$ Taken together, syringe swap error at induction involving muscle relaxants prompted the authors to comment that "special preventive measures should be taken to reduce errors in this group of drugs". ${ }^{1}$

With these results in mind, one must wonder if the size and shape of the syringe, despite being appropriately prepared and labelled, may contribute to such observations. Modification of a labelled syringe by taping the empty medication vial to the syringe barrel (Figure) may be useful to provide distinctive visual and proprioceptive feedback prior to administration of a muscle relaxant, particularly in the context of anesthesia induction where numerous different medications (often prepared in similar-sized syringes) are given in a relatively short time frame. Though formal studies have not been conducted regarding the efficacy of taping the empty medication vial to the syringe containing a neuromuscular blocking drug, this

C. L. Pysyk, MD, FRCPC ( $\square)$

Department of Anesthesiology and Pain Medicine, The Ottawa

Hospital, University of Ottawa, Ottawa, ON, Canada

e-mail: cpysyk@toh.on.ca low-cost, visual, and proprioceptive modification shares thematic similarities with and builds upon the:

1. Institute for Safe Medication Practices recommendations for preventing syringe swap by avoiding "look-alike medications, or look-alike packaging" $\mathrm{A}$ and standardization of medication preparation, ${ }^{\mathrm{B}}$

2. previously published suggestions for use of alternatesized syringes to differentiate neuromuscular blocking agents, ${ }^{2}$ and

3. Anesthesia Patient Safety Foundation opinion that "containers of different classes of medications should have different shapes and feel, adding touch to the senses involved in discriminating among drugs". ${ }^{3}$

Moreover, use of tactile differentiation to improve safety in perioperative care is not a new concept. For example, a change of the design and size of the oxygen delivery knob (found on non-digital anesthesia machines) was made to minimize the risk of wrong delivery gas selection (e.g., nitrous oxide instead of oxygen) from the anesthesia workstation. ${ }^{4}$

It is also worthwhile for providers to seek (and use if available in one's setting) medication vials with "peel-off labels for drugs drawn up in the operating room"4; these labels are commonly found on neuromuscular blocking

\footnotetext{
A Institute for Safe Medication Practices. Key Vulnerabilities In The Surgical Environment: Container Mix-Ups And Syringe SwapsNovember 2015. Available from URL: https://www.ismp.org/ newsletters/acutecare/showarticle.aspx $? \mathrm{id}=123$ (accessed February 2018).

B Institute for Safe Medication Practices Canada. Designing Effective Recommendations - April 2013. Available from URL: https://www.ismp-canada.org/download/ocil/ISMPCONCIL2013-4_ EffectiveRecommendations.pd (accessed February 2018).
} 


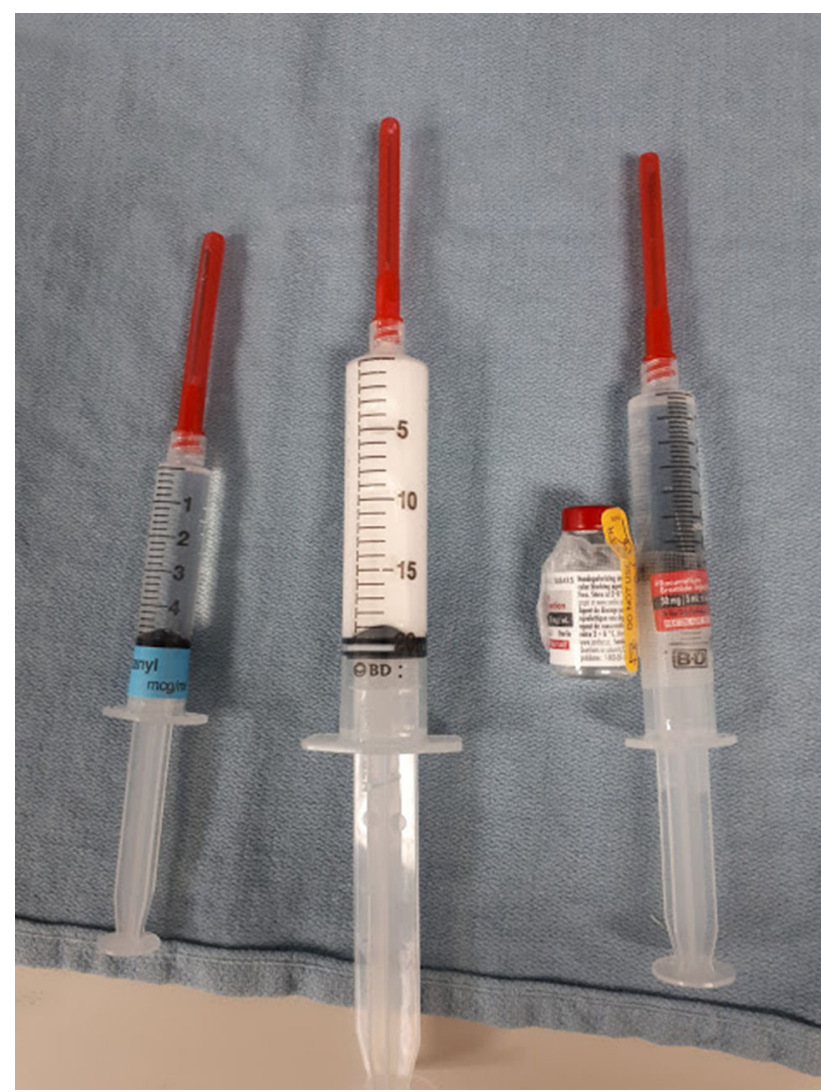

Figure An empty vial taped to barrel of syringe filled with the neuromuscular blocking drug rocuronium representing both a visual and tactile reminder of the unique contents of the syringe agent medication vials in use today. In addition, computerassisted bar-scan technologies also show promise and may help to reduce the risk of drug error in perioperative care. ${ }^{5}$ Nevertheless, regular use of such equipment in the perioperative domain remains incomplete. As such, some of our solutions for ongoing issues may indeed come from seeing and feeling the past for ideas.

Conflicts of interest None declared.

Editorial responsibility This submission was handled by Dr. Hilary P. Grocott, Editor-in-Chief, Canadian Journal of Anesthesia.

\section{References}

1. Fasting $S$, Gisvold SE. Adverse drug errors in anesthesia, and the impact of coloured syringe labels. Can J Anesth 2000; 47: 1060-7.

2. Pysyk $C L$. Syringe size and medication errors. Br J Anaesth 2016. DOI: https://doi.org/10.1093/bja/el_13566.

3. Eichhorn JH. "Syringe Swaps" in OR Still Harming Patients. Anesthesia Patient Safety Foundation (APSF). Available from URL: $\quad$ https://www.apsf.org/newsletters/html/2009/winter/04_ syringe.htm (Accessed February 2018)).

4. Ehrenwerth J, Eisenkraft J, Berry J. Anesthesia Equipment: Principals and Applications -. 2nd ed. NY: Elsevier Science Publishing Company Inc.; 2013.

5. Nanji KC, Patel A, Shaikh S, Seger DL, Bates DW. Evaluation of perioperative medication errors and adverse drug events. Anesthesiology 2016; 124: 25-34. 